\title{
Chapter 1 \\ Modelling the Cost and Benefits \\ of Adaptation. A Targeted Review \\ on Integrated Assessment Models \\ with a Special Focus on Adaptation \\ Modelling
}

\section{Reimund Schwarze, Quirin Oberpriller, Martin Peter, and Jürg Füssler}

\begin{abstract}
This paper gives a targeted review on Integrated Assessment Models (IAMs) with a focus on damage functions and adaptation modelling.
\end{abstract}

Keywords Adaptation modelling · IAMs

\section{Introduction}

Integrated Assessment Models (IAMs) can be roughly distinguished according to their objective as cross-sectoral optimization models (POMs) and economic assessment of climate policies (PEMs) according to Toth (2005). The first are welfareoriented optimal growth or general equilibrium models; the second are numerical simulation models for the cost minimization of climate policies in a partial oralso - a general equilibrium framework. The most popular models can be grouped according to this structure as in Table 1.1.

An evolutionary "family research" of IAMs helps to identify "generations" of models, where each generation enhanced the scientific understanding of climate change and influenced the economic recommendations for climate policy based on these models.

\author{
R. Schwarze ( $\square)$ \\ Helmholtz-Centre for Environmental Research-UFZ, Leipzig, Germany \\ e-mail: reimund.schwarze@ufz.de \\ Q. Oberpriller · M. Peter · J. Füssler \\ INFRAS-Forschung und Beratung, Zuerich, Switzerland \\ e-mail: quirin.oberpriller@infras.ch \\ M. Peter \\ e-mail: martin.peter@infras.ch \\ J. Füssler \\ e-mail: juerg.fuessler@infras.ch
}


Table 1.1 Types of IAMs

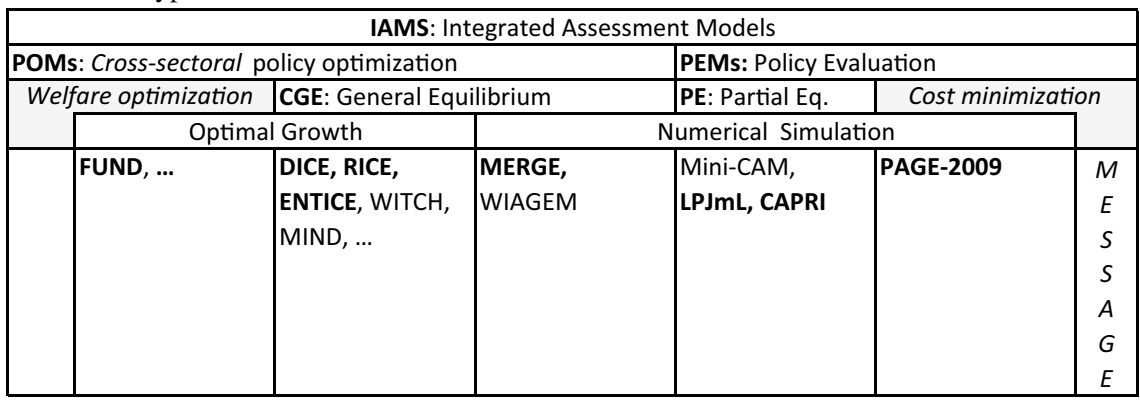

The first generation of models was developed in the 1990s as "basic models" that integrated climate modules and economic modules in one model. They all went through a period of "learning by doing" than "learning by investment", in short, they adsorbed endogenous growth theories that improved our understanding of the economic opportunities of a stringent climate policy, and ultimately shifted the 'optimal' or 'cost-efficient' policy paths towards demanding more and faster action against climate change. It was followed by a phase of learning on adaptation, often blended with geo-engineering which is the focus of this paper.

Effect-wise more important than all earlier are the two most recent generations of IAMs, which introduced climate catastrophes, economically speaking "fat tails" of climate risks, and the trend toward MIMI models, i.e. modularized, open sourcebased IAMs, which aim to overcome the popular criticism of a lack of transparency and black box-approaches of IAMs.

Figure 1.1 illustrates that not all model families have survived this process of "aging" and "learning", those that survived, re-acted to the scientific and societal critic by transformation.

Adaptation modelling challenges ahead.

Climate change impacts can be lowered by a variety of sectoral, regional and local adaptation measures. Including those in the damage function is a complex task for the following reasons:

- There are many climate-sensitive sectors each of which has specific adaptation measures, with respective costs and benefits in the short term and the long term.Especially for high temperatures, the benefits of adaption are highly uncertain (Fankhauser 2017).

- The extent and success of adaptation depends on the vulnerabilities and capabilities of regions and societies. Consider the example of the Netherlands and Bangladesh: Both will be highly affected by sea level rise, but the Netherlands is more able to handle such consequences, as the country is richer and has a long tradition of building sophisticated dikes. Damages will rise steeply if the adaptation capabilities of the affected societies are exceeded (Klein et al. 2008).

- The extent and form of adaptation is a choice by individuals and society. These choices may be modelled using a cost-benefit approach. Yet, information on 


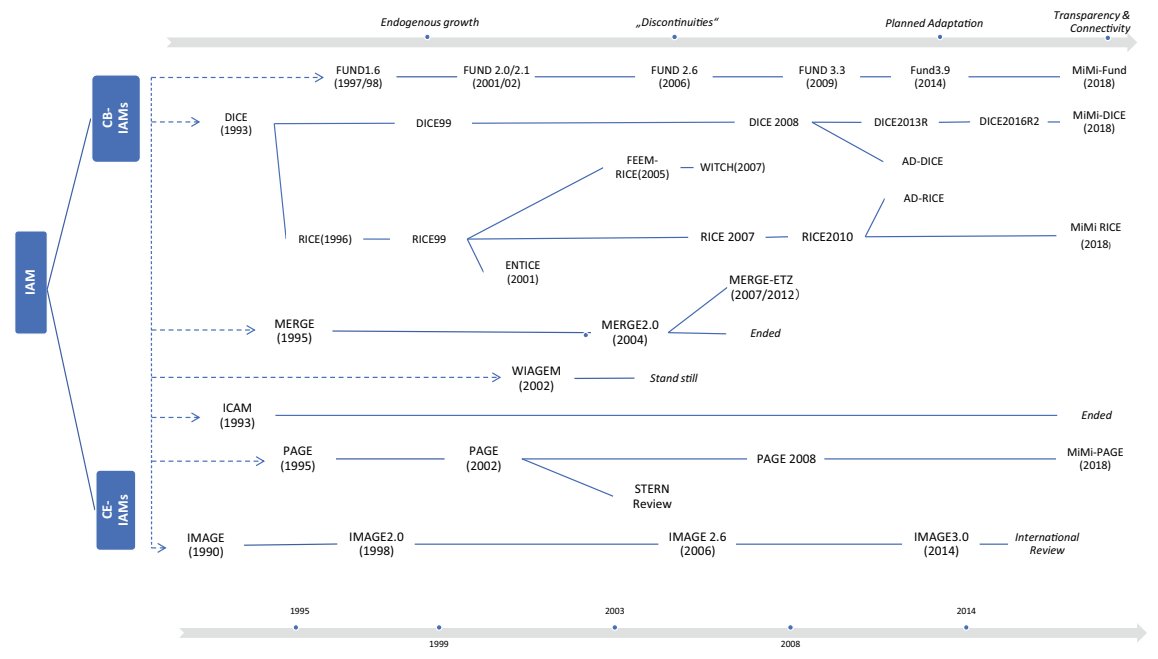

Fig. 1.1 History of IAMs

adaptation costs is scarce and local damages are uncertain. The literature on the costs and benefits of adaptation mainly considers coastal areas and agriculture.

IAMs dealing with adaptation.

Adaptation is incorporated in IAMs in very different ways (cp. Table 1.2):

- DICE considers adaptation implicitly. That is, the aggregate damage already includes the costs and benefits of adaptation (it is a "net" aggregate damage function). AD-DICE (de Bruin et al. 2009a, b) is an extension to DICE that explicitly considers adaptation. It disaggregates the damage function into adaptation costs and residual damages and selects a preferred combination of mitigation and adaptation.

- FUND introduces adaption for certain sectors explicitly. It includes an explicit cost-benefit analysis of costly coastal protection against sea level rise and assumes that parts of the agricultural damages (associated with the rate of climate change) fade with time at zero costs (autonomous adaptation). For other sectors, adaptation is implicit as in DICE (Diaz and Moore 2017; Estrada et al. 2019).

- PAGE introduces a tolerable temperature that increases with costly adaption measures. Damages are a function of the difference between the real and the tolerable temperature, such that, e.g. a real temperature increase of one degree without adaption causes the same damages as a real temperature increase of three degrees in case adaption has risen the tolerable temperature to two degrees.

- ICAM, MERGE and IMAGE consider geoengineering as an extreme form of adaptation, but at a different degree: some only as the carbon capture and storage (CCS), some also with CO2 removal (CDR) in different forms. To our knowledge, there is no IAM that would consider solar radiation management or ocean fertilization. 
Table 1.2 Adaptation modelling approaches properties of IAMs (POMs)

\begin{tabular}{l|l|l|l}
\hline Model & Regions & Damage function & $\begin{array}{l}\text { Adaptation / } \\
\text { Geoengineering }\end{array}$ \\
\hline DICE (DICE- 2013R) & Global & Linear-quadratic & Implicit \\
\hline RICE (RICE- 2010) & 12 & Quadratic, region-specific & Implicit \\
\hline FEEM-RICE 10 & 10 & Quadratic, region-specific & Implicit \\
\hline ENTICE & Global & Linear-quadratic & Implicit \\
\hline AD-DICE & Global & Linear-quadratic & $\begin{array}{l}\text { Explicit; reactive } \\
\text { adaptation }\end{array}$ \\
\hline AD-RICE & 12 & Quadratic, region-specific & $\begin{array}{l}\text { Explicit; reactive } \\
\text { adaptation }\end{array}$ \\
\hline FUND 3.9 & 16 & $\begin{array}{l}\text { Complex, different damage } \\
\text { functions (8 sectoral DF for } \\
\text { each region) }\end{array}$ & Implicit \\
\hline WITCH & 12 & Quadratic, region-specific & Implicit \\
\hline MERGE-ETL & Flexible & $\begin{array}{l}\text { Quadratic, considers } \\
\text { catastrophes }\end{array}$ & $\begin{array}{l}\text { Implicit/Geo-Engineering } \\
\text { (CCS, CDR) }\end{array}$ \\
\hline
\end{tabular}

Note CB-IAM $=$ Cost-Benefit Integrated Assessment Model CB-IAM weighs mitigation costs against the benefits of reducing climate damages within one model. POM = Policy-optimizing models or fully integrated IAMs (Toth 2005)

There are similar differentiations of concepts of adaptation in PEMs. Properties of IAMs (PEMs).

\begin{tabular}{l|l|l|l}
\hline Model & Regions & Damage function & $\begin{array}{l}\text { Adaptation / } \\
\text { Geoengineering }\end{array}$ \\
\hline ICAM & 17 & Complex & $\begin{array}{l}\text { Implicit/Geo-Engineering (CDR, } \\
\text { SRM) }\end{array}$ \\
\hline PAGE09 & 8 & $\begin{array}{l}\text { Power function with uncertain } \\
\text { exponent; considers catastrophes }\end{array}$ & Explicit; pro-active adaptation \\
\hline IMAGE 3.0 & 26 & Complex, biopysical feedbacks & $\begin{array}{l}\text { Implicit (adaptation potential); } \\
\text { soft-linking to GLOFRIS/FAIR / } \\
\text { Geo-Engineering (CCS, CDR) }\end{array}$ \\
\hline
\end{tabular}

Note CE-IAM only assesses mitigation costs for a predefined mitigation target. More specifically, it calculates the most cost-effective (i.e. least-cost) way. PEM = Policy-evaluation models (Toth 2005).

- Adaptation measures can be further separated into measures that act quickly (e.g. air conditioning) as well as precautionary measures (usually infrastructure with a longlife-span) as in Fankhauser (2017). The latter is aimed at average climate change (better insulation of houses against the increase in summer temperatures) or at protecting against extreme events (e.g. dikes against floods).

- Auffhammer (2018) defines extensive and intensive margin adaptation. The extensive margin response is due to the installation of new equipment (e.g. new air 
conditioning systems, irrigation equipment, sea walls, etc.). The intensive margin response means that existing equipment is used more frequently (the more frequent operation of existing air conditioners and irrigation equipment).

- Finally, the IPCC differentiates between adjustment costs (short-term costs of adaptation) and macro-scale adaptation (long-term restructuring of the economy). To correctly model the costs and benefits of adaptation all those different forms of adaptation have to be taken into account.

A special difficulty arises because adaptation costs can be seen as indirect damage costs. IAMs thus often blur the difference between direct damages (e.g. destructions caused by storms) and adaptation costs. In FUND, for example, the increasing energy cost of air conditioning is major damage sector, even though strictly speaking this is an adaptation measure. The corresponding decrease in damages (improved health) is not considered in FUND, even though a health sector exists. This obviously leads to an underestimation of the benefits of adaptation.

Another difficulty arises from the fact that the capacity for adaptation is a main defining element, and thus already explicitly considered for the SSPs. For example, in SSP1 and SSP5 the capacity to adapt is high, as there is a well-educated, rich population and a high development of technologies. In SSP1, there is in addition a good global governance and an intact ecosystem. In SSP3 and SSP4, on the other hand, the capacity is low due to the large, poor population, the lack of global cooperation, a slow technological development and unequal distribution of resources. These features have not yet been included in the damage functions in a harmonized manner.

\section{Conclusions and Recommendation}

To summarize, IAMs include adaptation explicitly (i.e. conducting a cost-benefit analysis of adaptation measures), implicitly (i.e. damage function is net of adaptation) or occurring autonomously (impacts fade at zero cost). In any case, these are highly aggregated approaches that do not consider the variety of adaptation possibilities at the local, regional and sectoral level. If at all, IAMs make very rough and adhoc assumptions on adaptation costs and benefits and do not include technological details. The understanding of (future) adaptive capacity, particularly in developing countries, through IAMs is still limited (Watkiss 2011). The extent and success of adaptation depends on the vulnerabilities and capabilities of regions and societies. In the face of all these shortcomings our recommendation, however, is not to give up on IAMs but to go through another phase of "aging and learning" of adaptation models that better fit to the heterogeneity of adaptation measures. 


\section{References}

Aufhammer M (2018) Climate adaptive response estimation: short and long run impacts of climate change on residential electricity and natural gas consumption using big data. NBER Working Paper No. w24397. Available at SSRN: https://ssrn.com/abstract=3138381

Ciscar JC, Goodess C, Christensen O, Iglesias A, Garrote L, Moneo M, Quiroga S, Feyen L, Dankers R, Nicholls R, Richards J (2009) Climate change impacts in Europe. Final report of the PESETA research project.

De Bruin KC, Dellink RB, Tol RSJ (2009a) AD-DICE: an implementation of adaptation in the DICE model. Clim Change 95:63-81

De Bruin KC, Dellink RB, Agrawala S (2009b) Economic aspects of adaptation to climate change: Integrated assessment modelling of adaptation costs and benefits, OECD Environment Working Papers 6

Diaz D, Moore F (2017) Quantifying the economic risks of climate change. Nat Clim Chang 7(774-782): 11

Dumas P, Hà Dưong M (2008) Optimal growth with adaptation to climate change. HAL, Working Papers. 117. https://doi.org/10.1007/s10584-012-0601-7

Estrada F, Tol RSJ, Botzen WJ (2019) Extending integrated assessment models' damage functions to include adaptation and dynamic sensitivity. Environ Model Softw 121. https://doi.org/10.1016/ j.envsoft.2019.104504

Fankhauser S (2017) Adaptation to Climate Change. Ann Rev Resour Econ 9. https://doi.org/10. 1146/annurev-resource-100516-033554

Klein RJT, Kartha S, Persson A, Watkiss P, Ackerman F, Downing TE, Kjellén B, Schipper L (2008) Adaptation: Needs, Financing and Institutions. Breaking the climate deadlock briefing paper. www.breakingtheclimatedeadlock.com

Oberpriller Q, Peter M, Füssler J, Zimmer A, Schaeffer M, Aboumahboub T, Schleypen J, Roming J, Schwarze R (2021) Climate cost modelling - analysis of damage and mitigation frameworks and guidance for political use. Report for the German environment agency (forthcoming)

Ortiz R, Markandya A (2010) Literature review of integrated impact assessment models of climate change with emphasis on damage function. BC3 Working Papers 6, Bilbao

Toth FL (2005) Coupling climate and economic dynamics: recent achievements and unresolved problems. In: Haurie A, Viguier L (eds) The coupling of climate and economic dynamics. Advances in global change research 22. Springer, Dordrecht

Watkiss P (2011) Aggregate economic measures of climate change damages: explaining the differences and implications. Wires Clim Change 2011(2):356-372

Open Access This chapter is licensed under the terms of the Creative Commons Attribution 4.0 International License (http://creativecommons.org/licenses/by/4.0/), which permits use, sharing, adaptation, distribution and reproduction in any medium or format, as long as you give appropriate credit to the original author(s) and the source, provide a link to the Creative Commons license and indicate if changes were made.

The images or other third party material in this chapter are included in the chapter's Creative Commons license, unless indicated otherwise in a credit line to the material. If material is not included in the chapter's Creative Commons license and your intended use is not permitted by statutory regulation or exceeds the permitted use, you will need to obtain permission directly from the copyright holder.



